Article

\title{
Antioxidant Activity of Brazilian Vegetables and Its Relation with Phenolic Composition
}

\author{
Ana P. Tiveron, Priscilla S. Melo, Keityane B. Bergamaschi, Thais M. F. S. Vieira, \\ Marisa A. B. Regitano-d'Arce and Severino M. Alencar * \\ Department of Agri-Food Industry, Food and Nutrition, "Luiz de Queiroz" College of Agriculture, \\ University of São Paulo, Piracicaba, SP, Av. Pádua Dias, 11, CEP 13418-900, Brazil; \\ E-Mails: anapaulativeron@gmail.com (A.P.T.); priscilla_esalq@yahoo.com.br (P.S.M.); \\ keityberga@yahoo.com.br (K.B.B.); tvieira@usp.br (T.M.F.S.V.); marisadarce@usp.br (M.A.B.R.A.) \\ * Author to whom correspondence should be addressed; E-Mail: smalencar@usp.br; \\ Tel.: +55-19-34294150; Fax: +55-19-34294288.
}

Received: 21 February 2012; in revised form: 9 June 2012 / Accepted: 10 July 2012 / Published: 18 July 2012

\begin{abstract}
Vegetables are widely consumed in Brazil and exported to several countries. This study was performed to evaluate the phenolic content and antioxidant activity of vegetables commonly consumed in Brazil using five different methods, namely DPPH and ABTS free radical, $\beta$-carotene bleaching, reduction of $\mathrm{Fe}^{3+}$ (FRAP), oxidative stability in Rancimat, and the chemical composition using gas chromatography-mass spectrometry (GC-MS). The content of phenolic compounds ranged from $1.2 \mathrm{mg} \mathrm{GA} / \mathrm{g}$ (carrot) to $16.9 \mathrm{mg}$ $\mathrm{GA} / \mathrm{g}$ (lettuce). Vegetables presenting the highest antioxidant activity were lettuce $(77.2 \mu \mathrm{mol}$ Trolox/g DPPH; $447.1 \mu \mathrm{mol} \mathrm{F}{ }^{2+} / \mathrm{g}$ FRAP), turmeric (118.6 $\mu \mathrm{mol}$ Trolox/g ABTS ${ }^{\circ+}$; $92.8 \%$ $\beta$-carotene), watercress and broccoli (protective factor 1.29-Rancimat method). Artichoke, spinach, broccoli, and asparagus also showed considerable antioxidant activity. The most frequent phenolic compounds identified by GC-MS were ferulic, caffeic, $p$-coumaric, 2-dihydroxybenzoic, 2,5-dihydroxybenzoic acids, and quercetin. We observed antioxidant activity in several vegetables and our results point out their importance in the diet.
\end{abstract}

Keywords: antioxidant activity; phenolic compounds; vegetables; GC-MS 


\begin{abstract}
Abbreviations
GC-MS: gas chromatography-mass spectrometry; GA: gallic acid; UV: ultraviolet; DPPH: 2,2-diphenyl-1-picryl-hydrazine; $\quad$ ABTS $^{*+}$ : 2,2'-azinobis-3-ethylbenzotiazoline-6-sulfonic acid; MSTFA: $N$-methyl- $N$-(trimethylsilyl)trifluoroacetamide; FRAP: ferric reducing antioxidant power; TPC: total phenolic content; $\mathrm{Fe}^{3+}-\mathrm{TPTZ}$ : ferric tripyridyltriazine; SPE: solid phase extraction; TMS: trimethylsilyl; GLM: general linear models; $\mathrm{IC}_{50}$ : inhibitory concentration; AA: antioxidant activity; DRc: control degradation rat; DRs: degradation rate in the presence of standard or vegetable extract; a: absorbance at initial time $(0 \mathrm{~min})$; $\mathrm{b}$ : absorbance at final time (120 min); BHT: butylated hydroxytoluene; IP: induction period; PF: protection factor; PIa: IP of the oil with the vegetable extracts or standards; Plc: IP of the control (oil without the vegetable extracts or standards); DW: dry weight.
\end{abstract}

\title{
1. Introduction
}

Vegetables are widely produced in Brazil both for local consumption and export to several countries. Brazil is a country that presents great agro-ecological diversity and a large production of vegetables. Recent studies have shown the importance of vegetables in a healthy diet and to prevent degenerative diseases caused by oxidative stress [1]. Vitamins and phytochemicals, such as ascorbic acid, carotenoids, polyphenols, and fiber have been regarded as the bioactive substances responsible for these effects [2].

Phenolic compounds are secondary metabolites commonly found in plants, useful in the defensive function against pathogens and radiation, and are directly involved in the antioxidant activity [3-5].

Antioxidants can be defined as any substance that, present in low concentration compared to an oxidized substrate, effectively delays or inhibits oxidation of the substrate [6]. For the food industry, it is also highly interesting to find new and safe antioxidants from natural sources. Although synthetic antioxidants are very effective and stable, they have limited use in many countries due to the possibility of causing adverse effects on human health $[7,8]$.

Several techniques have been used to determine the in vitro antioxidant activity in order to allow rapid screening of promising substances and/or mixtures. In the last few years, evaluation of the antioxidant potential of food, as well as natural, pharmaceutical, and cosmetic products has been increasing. The interest on this field began to expand in the 1990s based on the observation that many natural products have beneficial effects on human health. Furthermore, the research and validation of methodologies for evaluating the antioxidant activity in complex matrices such as food, natural products, and biological fluids have also been improved $[5,9,10]$. Although many methods have been developed and tested in the literature, their advantages and limitations are still under discussion and no consensus has been reached to define a unique standard method capable of encompassing all the peculiarities exhibited by the different classes of antioxidants [11]. Many methods are available for analyzing antioxidant activity, with different concepts, mechanisms of action, ways of expressing results, and applications [12-14]. On the one hand, indirect methods, involving electron transfer reactions, such as $\mathrm{ABTS}^{\circ+}$, $\mathrm{DPPH}^{\circ}$, and FRAP, are easier to apply, but present some limitations. In this case, the methods evaluate the free radical scavenging ability of antioxidant compounds, and this does not necessarily correspond to the real oxidative degradation, although, in some circumstances, the 
donation of hydrogen atoms (or electrons) correlates with the antioxidant activity. On the other hand, according to Becker et al. [15], direct methods, such as $\beta$-carotene and Rancimat, are characterized by their ability to inhibit or halt lipid oxidation in model systems, based on measuring changes in the concentration of compounds being oxidized, on oxygen depletion, or on formation of oxidation products. Therefore, since these chemically distinct methods are based on different reaction mechanisms, it is important to use different methods in order to obtain a more thorough assessment of the antioxidant potential of a sample $[10,16]$. Several analytical methods have been used to evaluate antioxidant activity by free radical scavenging, but besides being one of the fastest, ABTS $^{\circ+}$ method also provides good solubility, which allows the analyses of both lipophilic and hydrophilic compounds [17].

This study evaluates the antioxidant activity properties of the main vegetables produced and consumed in Brazil. Antioxidant properties are determined in various test systems with different mechanisms of action, including antioxidant activity by scavenging abilities on DPPH (2,2-diphenyl-1picrylhydrazyl radical) and ABTS (2,2'-azinobis-3-ethylbenzotiazoline-6-sulfonic acid radical), reducing power test, $\beta$-carotene bleaching and oxidative stability by the Rancimat method. Content and profile of potential antioxidant in these vegetables are also examined.

\section{Results and Discussion}

Phenolic compounds are responsible for the antioxidant activity of vegetables. Although in recent years the antioxidant analysis of vegetables has been extensively researched worldwide [18-22], very few studies have been carried out to assess vegetables grown in Brazil and consumed locally or exported to several countries.

The content of phenolic compounds found in our samples ranged from 1.2 to $16.9 \mathrm{mg} \mathrm{GA} / \mathrm{g}$ sample (dry weight - DW), in carrot and lettuce, respectively (Figure 1). These results were different from the findings reported by $\mathrm{Chu}$ et al. [23], since in their study lettuce was one of the vegetables that presented the lowest total phenolic content, using the same method. Llorach et al. [22] found higher levels of phenolic compounds in red-leafed varieties of lettuce compared to green ones. According to Gobbo-Neto and Lopes [24], several factors such as seasonality, temperature, water availability, UV radiation, soil nutrients, pollution, and pathogen attack can affect the content of secondary metabolites in vegetables, such as phenolic compounds.

Figure 1. Content of phenolic compounds (mg GA/g of DW) in several vegetables grown in Brazil; means followed by different letters differ statistically $(p<0.05)$ by Tukey test.

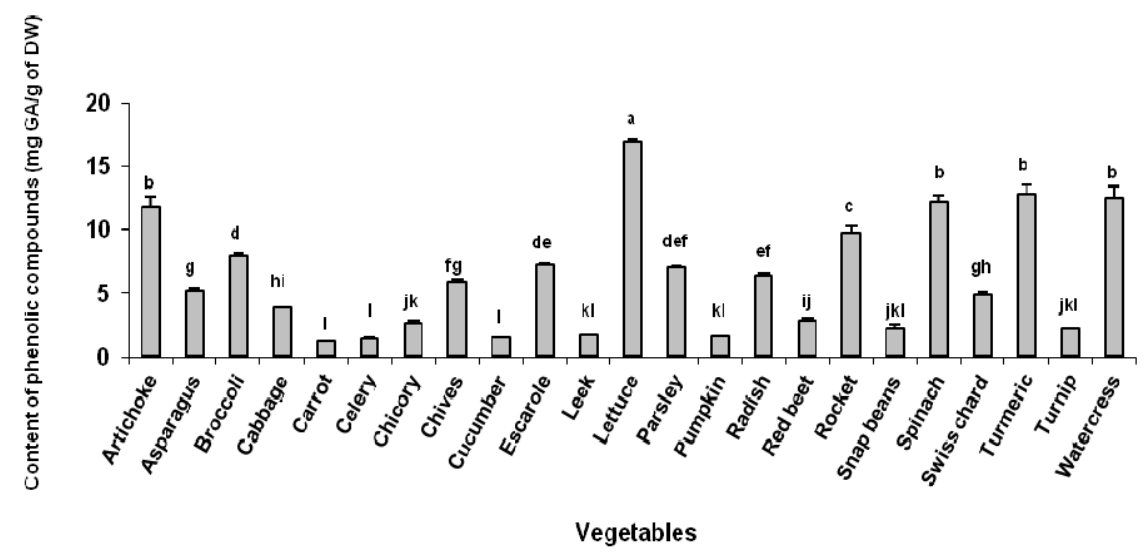


According to the literature, phenolic compounds found in plants have antioxidant and anticancer activities. In this regard, some authors highlighted the antioxidant activity of curcumin, a naturally occurring phenolic compound of turmeric that is responsible for its peculiar color and important antioxidant and anticancer activities [25-27].

The results presented in Table 1 show that using the $\mathrm{ABTS}^{\circ+}$ method, turmeric had the highest antioxidant activity $(118.6 \mu \mathrm{mol}$ Trolox/g), followed by watercress $(97.1 \mu \mathrm{mol}$ Trolox/g) and lettuce (85.8 $\mu \mathrm{mol}$ Trolox/g).

The analysis of the antioxidant activity of commonly consumed vegetables grown in Colorado (USA) using the $\mathrm{ABTS}^{\circ+}$ method showed that spinach and broccoli presented antioxidant activity of approximately $50 \mu \mathrm{mol}$ Trolox/g and $40 \mu \mathrm{mol}$ Trolox/g, respectively, a result similar to our findings, of $41.2 \mu \mathrm{mol}$ Trolox/g and $43.0 \mu \mathrm{mol}$ Trolox/g, respectively [20].

Turmeric (92.8\%) and lettuce $(90 \%)$ showed the highest antioxidant activity by the $\beta$-carotene bleaching method, while turnip (3.4\%) presented the lowest result. One factor that may influence this analysis is the medium where the reaction occurs, characterized as an emulsion, with polar and non-polar regions simultaneously. Therefore, depending on the polarity of the sample, it can interact more or less intensely with the emulsion.

The highest ability to reduce $\mathrm{Fe}^{3+}$ to $\mathrm{Fe}^{2+}$ was found in lettuce (447.1 $\mu \mathrm{mol} \mathrm{Fe} \mathrm{Fe}^{2+} / \mathrm{g}$ ), watercress $\left(277.4 \mu \mathrm{mol} \mathrm{Fe} e^{2+} / \mathrm{g}\right)$, and spinach $\left(273.3 \mu \mathrm{mol} \mathrm{Fe}{ }^{2+} / \mathrm{g}\right)$ (Table 1). Studying wild artichoke from Slovakia, Kukić et al. [28] reported $350 \mu \mathrm{mol} \mathrm{Fe}{ }^{2+} / \mathrm{g}$ in dry basis for ethanol extracts, and $340 \mu \mathrm{mol} \mathrm{Fe} \mathrm{e}^{2+} / \mathrm{g}$ for aqueous extracts. In contrast, in the present study, Brazilian artichoke showed much lower ability to reduce $\mathrm{Fe}^{3+}\left(98.7 \mu \mathrm{mol} \mathrm{Fe}{ }^{2+} / \mathrm{g}\right)$.

The Rancimat method is widely used for the determination of the oxidative stability of natural fats and oils. The induction period is characterized by change in conductivity of deionized water due to oxidation-generated products. The process is carried out under high temperatures and constant aeration. All vegetables tested, except the escarole, had a longer induction period compared to the control (pure soybean oil, without added antioxidants), with a protection factor and consequent antioxidant activity (Table 1). The vegetables that showed the highest protection factors were watercress (1.29), broccoli (1.29) and chives (1.24), while escarole showed no protection against lipid oxidation. It could be inferred that, except for escarole, soybean oil added to vegetable extracts required a longer time to form free radicals, reactive molecules that trigger the initiation phase of the oxidation process, thus delaying the propagation phase and, consequently, the termination phase.

The highest antioxidant activities by the $\mathrm{DPPH}^{\circ}$ method were found in lettuce, artichoke, turmeric, spinach, escarole, and watercress $(77.2,70.1,57.6,50.9,48.1$, and $44.0 \mu \mathrm{mol}$ Trolox $/ \mathrm{g}$, respectively) (Table 1). 
Table 1. Antioxidant activity of commonly consumed vegetables in Brazil.

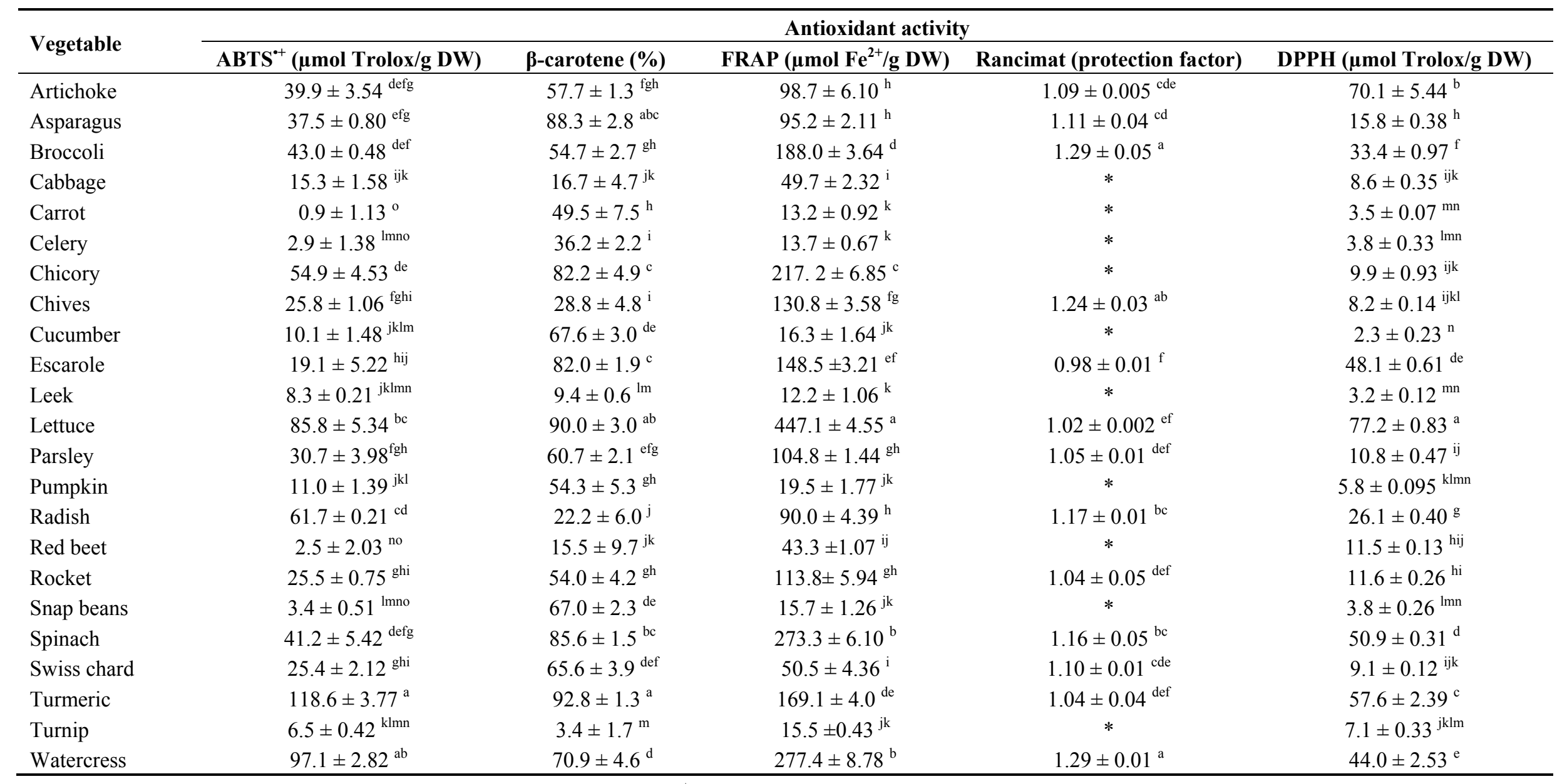

Reference values: BHT $(100 \mathrm{ppm})-1666.1 \pm 6.0 \mu \mathrm{mol}$ Trolox/g $\left(\mathrm{ABTS}^{+}\right)$; $93.9 \pm 0.21 \%$ ( $\beta$-carotene); $11762.0 \pm 1.5 \mu \mathrm{mol}$ Trolox/g (FRAP); $1.10 \pm 0.090$ (Rancimat); $200.4 \pm 0.3 \mu \mathrm{mol}$ Trolox/g (DPPH); $\alpha$-tocopherol $(100 \mu \mathrm{ppm})-2855.2 \pm 1.9 \mu \mathrm{mol}$ Trolox $/ \mathrm{g}\left(\mathrm{ABTS}^{+}\right) ; 88 \pm 1.6 \%$ ( $\beta$-carotene); $3462.9 \pm 3.4 \mu \mathrm{mol}$ Trolox $/ \mathrm{g}$ (FRAP); $1507.0 \pm 1.2 \mu \mathrm{mol}$ Trolox/g (DPPH); Values represent the average of triplicates \pm standard deviation; means followed by different letters in the same column differ statistically $(p<0.05)$ by the Tukey test. * Induction period not calculated due to the large amount of samples required to achieve the concentration of $100 \mathrm{ppm}$ of total phenolic compounds; $\mathrm{ABTS}^{+}:$2,2'-azinobis-3-ethylbenzotiazoline-6-sulfonic acid; FRAP: ferric reducing antioxidant power; DPPH: 2,2-diphenyl-1-picryl-hydrazine. 
Based on the highest results using the $\mathrm{DPPH}^{*}$ method, the $\mathrm{IC}_{50}$ of lettuce, artichoke, turmeric, spinach, and escarole were calculated and are shown in Figure 2. The vegetable that showed the lowest extract concentration to reduce the initial amount of DPPH radical by $50 \%$ was lettuce $(17.07 \mathrm{mg} / \mathrm{mL})$, followed by artichoke $(18.14 \mathrm{mg} / \mathrm{mL})$, turmeric $(21.14 \mathrm{mg} / \mathrm{mL})$, spinach $(22.87 \mathrm{mg} / \mathrm{mL})$, and escarole $(32.2 \mathrm{mg} / \mathrm{mL})$. Vegetables presenting the lowest $\mathrm{IC}_{50}$ values can be considered better in terms of antioxidant activity, since a lower concentration to reduce the DPPH free radical by $50 \%$ is required.

Figure 2. Concentration of vegetable extract required to reduce the initial DPPH radical by $50 \%$.

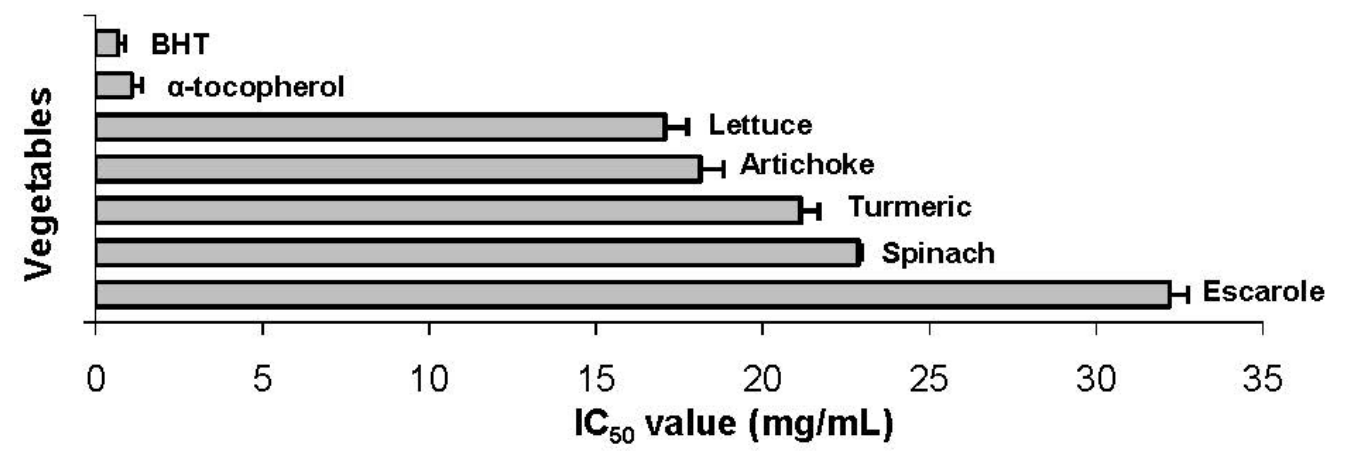

All vegetables except for escarole have considerable amounts of total phenolic compounds and consequent significant antioxidant activity. The correlation between them becomes important and is presented in Table 2.

Table 2. Pearson's correlation coefficient between total phenolic compounds (TPC) and total antioxidant activity.

\begin{tabular}{lcc}
\hline Correlation & $\boldsymbol{r}$ & $\boldsymbol{r}^{\mathbf{2}} \mathbf{( \% )}$ \\
\hline TPC $v$ s. DPPH & 0.89 & 80.64 \\
TPC $v$ s. $\beta$-carotene & 0.52 & 27.49 \\
TPC $v$ s. ABTS & 0.79 & 61.85 \\
TPC $v$ s. FRAP & 0.82 & 68.60 \\
TPC $v$ s. Rancimat & 0.18 & 3.47 \\
\hline
\end{tabular}

TPC: total phenolic content; DPPH: 2,2-diphenyl-1-picryl-hydrazine; ABTS: 2,2'-azinobis-3-ethylbenzotiazoline6-sulfonic acid; FRAP: ferric reducing antioxidant power.

The amount of phenolic compounds found in the vegetables evaluated in this study showed no direct relationship with their antioxidant activity using some methods. The lowest correlation between phenolic compound content and antioxidant activity was observed for the Rancimat method $\left(r^{2}=3.47 \%\right)$, whereas the DPPH ${ }^{\circ}$ and FRAP methods $(80.64 \%$ and $68.60 \%$, respectively) showed the highest correlations.

Table 3 shows the correlation between the methodologies used in this study to evaluate antioxidant activity in vegetables. The results reveal lack of consistency among these methodologies. This fact could be explained by the different characteristics and mechanisms of action of the bioactive compounds present in the samples as well as the different principles used to detect antioxidant properties in each method. 
Table 3. Pearson's correlation coefficient between the different antioxidant activity methodologies.

\begin{tabular}{lcc}
\hline Correlation & $\boldsymbol{r}$ & $\boldsymbol{r}^{\mathbf{2}} \mathbf{( \% )}$ \\
\hline DPPH vs. $\beta$-carotene & 0.52 & 27.36 \\
DPPH vs. ABTS & 0.71 & 51.03 \\
DPPH vs. FRAP & 0.75 & 56.65 \\
DPPH vs. Rancimat & 0.22 & 4.93 \\
$\beta$-carotene $v$ s. ABTS & 0.53 & 28.67 \\
$\beta$-carotene $v$ s. FRAP & 0.58 & 34.07 \\
$\beta$-carotene $v$ s. Rancimat & 0.44 & 19.9 \\
ABTS vs. FRAP & 0.74 & 56.08 \\
ABTS vs. Rancimat & 0.09 & 0.97 \\
FRAP vs. Rancimat & 0.03 & 0.09 \\
\hline
\end{tabular}

DPPH: 2,2-diphenyl-1-picryl-hydrazine; ABTS: 2,2'-azinobis-3-ethylbenzotiazoline-6-sulfonic acid; FRAP: ferric reducing antioxidant power.

The best correlations were found for $\mathrm{DPPH}^{\bullet} v s$. FRAP $(56.65 \%)$ and $\mathrm{ABTS}^{\circ+} v s$. FRAP $(56.08 \%)$, while the Rancimat vs. FRAP did not show a good correlation $(0.09 \%)$. The method that best correlated with Rancimat was $\beta$-caroten (19.9\%), both considered direct methods.

Therefore, despite the difficulty to choose the most appropriate method for the evaluation of antioxidant activity, the most commonly accepted, validated, and standardized methods, with more information available should be chosen.

The results of the phenolic composition obtained using GC-MS are presented in Table 4. Several compounds derived from benzoic acid (3-hydroxybenzoic, syringic, 2,5-dihydroxybenzoic, 2-hydroxybenzoic, gallic, and 2,4-dihydroxybenzoic acids) and from cinnamic acid (sinapic, $p$-coumaric, and caffeic acids) were found. The most abundant phenolic compound derived from cinnamic acid present in the samples assessed in this study was caffeic acid, and spinach (53.54\%) showed the greatest amount of this compound.

Regarding flavonoids, quercetin was found in lettuce $(2.02 \%)$, chicory $(1.32 \%)$, asparagus $(5.56 \%)$ chives $(0.93 \%)$ and snap beans $(8.67 \%)$ and kaempferol in chives $(4.60 \%)$, snap beans $(3.41 \%)$, and escarole (3.19\%), already known for its high antioxidant activity (Table 4). Llorach et al. [22] detected luteolin and quercetin derivatives in lettuce, in amounts that varied according to the cultivar. DuPont et al. [29] analyzed the flavonoids of Cichorium endivia in the United Kingdom, and also identified the presence of kaempferol, corroborating the results found in this work.

The ascorbic acid identified in some of our samples may have contributed to the antioxidant activity of vegetables, such as in the cases of broccoli, cabbage, chives, parsley, rocket, and watercress, since this is a compound with high electron donation capacity. 
Table 4. Concentration (\%) of compounds identified in ethanol extracts of the vegetables analyzed using GC-MS.

\begin{tabular}{|c|c|c|c|c|c|c|c|c|c|c|c|c|c|c|}
\hline \multirow{2}{*}{ Vegetable ethanol extract } & \multicolumn{14}{|c|}{ Area of the component (\%) } \\
\hline & 1 & 2 & 3 & 4 & 5 & 6 & 7 & 8 & 9 & 10 & 11 & 12 & 13 & 14 \\
\hline Artichoke & - & - & - & 0.01 & - & - & - & - & - & 32.46 & - & - & - & - \\
\hline Asparagus & - & - & - & - & 0.15 & - & - & - & 2.61 & 1.40 & - & 5.56 & - & - \\
\hline Broccoli & 1.12 & - & - & - & 0.51 & - & 6.72 & - & 1.95 & 0.31 & - & - & - & - \\
\hline Cabbage & 0.63 & - & - & - & - & - & 12.61 & 0.41 & 12.61 & 0.28 & - & - & - & - \\
\hline Carrot & - & 0.13 & - & - & - & - & - & 0.42 & - & 0.49 & - & - & 0.78 & - \\
\hline Celery & - & - & - & 1.68 & - & - & - & - & 1.08 & 9.88 & - & - & - & 0.99 \\
\hline Chicory & - & - & - & - & - & - & - & 0.39 & - & 47.04 & - & 1.32 & - & - \\
\hline Chives & 0.26 & - & - & - & - & - & 0.10 & 2.72 & 15.60 & 0.56 & 4.60 & 0.93 & 0.12 & - \\
\hline Cucumber & - & - & - & 1.43 & 14.23 & - & - & - & 0.22 & - & - & - & - & - \\
\hline Escarole & - & - & - & - & - & - & - & - & 0.22 & 42.53 & 3.19 & - & - & - \\
\hline Leek & - & - & - & - & - & - & - & 0.19 & 0.96 & - & - & - & - & - \\
\hline Lettuce & - & - & - & - & - & - & - & 0.60 & - & 26.92 & - & 2.02 & - & 0.16 \\
\hline Parsley & 1.08 & - & - & 0.06 & 0.82 & - & - & - & - & 0.14 & - & - & - & 0.41 \\
\hline Pumpkin & - & - & - & - & - & 0.32 & - & - & - & - & - & - & - & - \\
\hline Radish & - & 0.89 & - & - & - & - & - & 1.81 & 1.81 & 1.18 & - & - & - & - \\
\hline Red beet & - & - & 9.54 & 0.52 & - & - & - & 0.43 & 0.82 & - & - & - & - & - \\
\hline Rocket & 5.31 & - & - & 0.14 & - & - & 0.21 & - & - & - & - & - & - & - \\
\hline Snap beans & - & - & - & - & 1.14 & - & - & 2.63 & 0.71 & 0.50 & 3.41 & 8.67 & 9.73 & 1.67 \\
\hline Spinach & - & - & - & - & - & - & - & - & 1.60 & 53.54 & - & - & - & - \\
\hline Swiss chard & - & - & - & - & 0.24 & - & 10.85 & - & 1.38 & - & - & - & - & - \\
\hline Turmeric & - & - & - & - & - & - & - & - & - & - & - & - & 0.57 & 0.35 \\
\hline Turnip & - & 0.96 & - & - & - & - & - & 0.42 & 0.78 & - & - & - & - & - \\
\hline Watercress & 10.90 & - & - & - & - & - & 0.48 & 0.13 & 0.60 & 0.66 & - & - & - & - \\
\hline
\end{tabular}

1: Ascorbic acid; 2: 3-hydroxybenzoic acid; 3: Syringic acid; 4: 2,5-dihydroxybenzoic acid; 5: 2-hydroxybenzoic acid; 6: Gallic acid; 7: Sinapic acid; 8: $p$-coumaric acid; 9: Ferulic acid; 10: Caffeic acid; 11: Kaempferol; 12: Quercetin; 13: Isovanillic acid; 14: 2,4-dihydroxybenzoic acid; GC-MS: gas cromatography-mass spectrometry. 


\section{Experimental Section}

\subsection{Chemicals and Reagents}

Gallic acid, 2,2-diphenyl-1-picryl-hydrazine (DPPH'), 2,2'-azinobis-3-ethylbenzotiazoline-6-sulfonic acid $\left(\mathrm{ABTS}^{\circ+}\right), \beta$-carotene, linoleic acid, ferric chloride, ferrous sulfate, tripyridyltriazine, $N$-methyl- $N$-(trimethylsilyl)trifluoroacetamide (MSTFA), and standards for GC-MS were purchased from Sigma-Aldrich (St. Louis, MO, USA). The other reagents were purchased from local sources. The cartridges used for SPE-LC18 chromatographic analysis were obtained from Supelco (Bellefonte, PA, USA).

\subsection{Sample Collection and Extraction}

All the vegetables used were produced in the São Paulo State, in Southeastern Brazil, wet tropical climate, $22^{\circ} 43^{\prime} 31^{\prime \prime} \mathrm{S}$ and $47^{\circ} 38^{\prime} 57^{\prime \prime} \mathrm{W}$, from January to October. The following vegetable species were assessed: (1) artichoke (Cynara scolymus L.); (2) asparagus (Asparagus officinalis L.); (3) broccoli (Brassica oleracea L. var. italic Plenck); (4) cabbage (Brassica oleracea L. var. capitata); (5) carrot (Daucus carota L.); (6) celery (Apium graveolens L.); (7) chicory (Cichorium intybus L.); (8) chives (Allium fistolosum L.); (9) cucumber (Cucumis sativus L.); (10) escarole (Cichorium endivia L.); (11) leek (Allium porrum L.); (12) lettuce (Lactuca sativa L.); (13) parsley (Petroselinum crispum (Mill.) Nym.); (14) pumpkin (Cucurbita maxima Duch.); (15) radish (Raphanus sativus L.); (16) red beet (Beta vulgaris L.); (17) rocket (Eruca sativa L.); (18) snap beans (Phaseolus vulgaris L.); (19) spinach (Tetragonia expansa L.); (20) Swiss chard (Beta vulgaris L. var. cicla); (21) turmeric (Curcuma longa L.); (22) turnip (Brassica rapa L.); (23) watercress (Nasturtium officinale).

The extraction of the compounds of interest from the vegetable samples was performed according to the method described by Kähkönen et al. [3] with some modifications. Samples were first frozen at $-18{ }^{\circ} \mathrm{C}$ and then lyophilised. After that, the material was ground and $1 \mathrm{~g}$ of each vegetable powder was placed in Falcon tubes, mixed with $20 \mathrm{~mL}$ of $80 \%$ ethanol (v/v), and shaken thoroughly. Subsequently, the tubes were sonicated for $5 \mathrm{~min}$, centrifuged for $15 \mathrm{~min}$ at $5000 \times \mathrm{g}$, and the supernatant collected for analysis. All samples were extracted in triplicate.

\subsection{Determination of Total Phenolic Content}

Total phenolic content analysis was performed using the Folin Ciocalteau spectrophotometric method described by Singleton et al. [30,31]. The vegetable extracts were diluted in ethanol $80 \%$ and $0.5 \mathrm{~mL}$ of the solution obtained was transferred to a tube with $2.5 \mathrm{~mL}$ of Folin Ciocalteau reagent diluted in water at 1:10. The mixture was allowed to sit for 3-8 min, then $2 \mathrm{~mL}$ of sodium carbonate $4 \%$ was added, and the tubes were kept in the dark for $2 \mathrm{~h}$. Afterwards, the absorbance was measured at $740 \mathrm{~nm}$ using a UV-mini 1240 spectrophotometer (Shimadzu, Japan). A blank test was also performed under the same conditions and the results of total phenolic compounds were expressed as gallic acid equivalent (mg GA/g sample DW), based on a calibration curve of gallic acid in the concentration range of 5 to $80 \mu \mathrm{g} / \mathrm{mL}$. 


\subsection{DPPH Free Radical Scavenging Assay and $I C_{50}$}

The reaction mixture consisted of $0.5 \mathrm{~mL}$ of standards or vegetable extracts, $3.0 \mathrm{~mL}$ of pure ethanol, and $0.3 \mathrm{~mL}$ of DPPH radical in ethanol solution $0.5 \mathrm{mM}$, which was incubated at room temperature for $45 \mathrm{~min}$, and the activity was expressed in $\mu \mathrm{mol}$ Trolox/g of sample DW [32]. The calibration curve was constructed with the standard Trolox in the concentration range of 0 to $200 \mu \mathrm{M}$ Trolox.

Several vegetable extract concentrations were used, and readings were monitored at $517 \mathrm{~nm}$, using a UV-mini 1240 spectrophotometer (Shimadzu, Japan), every $20 \mathrm{~min}$ for 140 or $160 \mathrm{~min}$, depending on the sample, until a constant reading was obtained. The antioxidant activity measured by DPPH free radical method can be expressed as $\mathrm{IC}_{50}$, i.e., the antioxidant concentration required to reduce the initial DPPH radical by $50 \%$. The concentration of vegetable samples required to reduce the initial DPPH radical by $50 \%$ is expressed in $\mathrm{mg} / \mathrm{mL}$.

\subsection{Antioxidant Activity Using $\beta$-Carotene Bleaching Method}

The antioxidant activity assessment was performed according to the method described by Emmons et al. [33] with some modifications. An emulsion was prepared by dissolving $10 \mathrm{mg}$ of $\beta$-carotene in $100 \mathrm{~mL}$ of chloroform PA and aliquots of $3 \mathrm{~mL}$ were added to $40 \mathrm{mg}$ of linoleic acid and $400 \mathrm{mg}$ of Tween 40. The chloroform was removed using a stream of nitrogen and the residue obtained was redissolved in $100 \mathrm{~mL}$ of water aerated for $30 \mathrm{~min}$. Aliquots of $3 \mathrm{~mL}$ of the resultant $\beta$-carotene/linoleic acid emulsion were mixed with $50 \mu \mathrm{L}$ of the vegetable extracts and incubated in a water bath at $50{ }^{\circ} \mathrm{C}$. The emulsion oxidation was monitored using a UV-mini 1240 spectrophotometer (Shimadzu, Japan) at $470 \mathrm{~nm}$, at baseline and at 20-min intervals for $2 \mathrm{~h}$. Control samples contained only solvent in place of the vegetable extracts. BHT and $\alpha$-tocopherol (200 ppm) were used as reference standards. The antioxidant activity was expressed as percentage of relative inhibition compared to control samples after $120 \mathrm{~min}$ and calculated as:

$$
\% \mathrm{AA}=[(\mathrm{DRc}-\mathrm{DRs}) / \mathrm{DRc}] \times 100
$$

where $\mathrm{AA}=$ antioxidant activity; $\mathrm{DRc}=$ control degradation rate $(\ln (\mathrm{a} / \mathrm{b}) / 120)$; DRs $=$ degradation rate in the presence of standard or vegetable extract $(\ln (\mathrm{a} / \mathrm{b}) / 120)$; $a=$ absorbance at initial time (0 min); $b=$ absorbance at final time (120 min).

\subsection{Antioxidant Activity Using $A B T S^{+}$Assay}

The antioxidant activity by the $\mathrm{ABTS}^{\circ+}$ method (2,2'-azinobis-3-ethylbenzotiazoline-6-sulfonic acid) was assessed according to the method described by Re et al. [17] with modifications. The ABTS radical was formed through the reaction of $\mathrm{ABTS}^{\circ+}$ solution $7 \mathrm{mM}$ with potassium persulfate solution $140 \mathrm{mM}$, incubated at $25^{\circ} \mathrm{C}$ in the dark for $12-16 \mathrm{~h}$. Once formed, the radical was diluted with ethanol P.A. to an absorbance of $0.700 \pm 0.020$ at $734 \mathrm{~nm}$. Three different dilutions of each vegetable extract were prepared in triplicate. After that, $30 \mu \mathrm{L}$ of each vegetable extract dilution were transferred to test tubes with $3.0 \mathrm{~mL}$ of ABTS radical in the dark. The absorbance was read at $734 \mathrm{~nm}$ after 6 min of the reaction using ethanol as a blank. Trolox, a synthetic water-soluble antioxidant analogue of vitamin E, 
was used as reference at concentrations ranging from 100 to $2000 \mu \mathrm{M}$ and the results were expressed as $\mu \mathrm{M}$ Trolox/g sample.

\subsection{Ferric Reducing Antioxidant Power Assay (FRAP)}

To determine the antioxidant activity by iron reduction, using the ferric reducing antioxidant power (FRAP) assay, we followed the methodology described by Benzie and Strain [34] with some modifications. FRAP measures the ferric reducing ability of the samples, in acidic medium ( $\mathrm{pH} 3.6$ ), forming an intense blue color as the ferric tripyridyltriazine ( $\mathrm{Fe}^{3+}$-TPTZ) complex is reduced to the ferrous $\left(\mathrm{Fe}^{2+}\right)$ form. FRAP reagent was prepared immediately before analysis by mixing $25 \mathrm{~mL}$ of acetate buffer (300 mM, pH 3.6), $2.5 \mathrm{~mL}$ of TPTZ solution (10 mM TPTZ in $40 \mathrm{mM} \mathrm{HCl})$, and $2.5 \mathrm{~mL}$ of $\mathrm{FeCl}_{3}(20 \mathrm{mM})$ in aqueous solution. An aliquot of $100 \mu \mathrm{L}$ of the vegetable extracts was added to $3 \mathrm{~mL}$ of FRAP reagent and incubated in a water bath at $37{ }^{\circ} \mathrm{C}$ for $30 \mathrm{~min}$. After this time, the absorbance was measured using a UV-mini 1240 spectrophotometer (Shimadzu, Japan) that was reset with FRAP solution. The calibration curve was constructed using ferrous sulfate $(100-2000 \mu \mathrm{M})$ and the results were expressed in $\mu \mathrm{mol} \mathrm{Fe}^{2+} / \mathrm{mg}$.

\subsection{Oxidative Stability-Rancimat}

Samples of $5 \mathrm{~g}$ of pure soybean oil (supplied by Cargill, without added antioxidants) were mixed with the vegetable extracts at a concentration of $100 \mathrm{ppm}$, based on the content of phenolic compounds. The oxidative stability index of this mixture was measured by the Rancimat method according to AOCS Cd 12b-92 [35] at $110 \pm 1{ }^{\circ} \mathrm{C}$ and a flow rate of $9 \mathrm{~L} / \mathrm{h}$ of dry air, using 743 Rancimat (Metrohm AG, CH-9100 Herisau, Switzerland). The conductivity increase due to the accumulation of oxidized compounds plotted as a function of the reaction time allowed the construction of the curve and the calculation of the induction period (IP). A control was prepared with pure soybean oil without added antioxidants and samples containing synthetic antioxidant BHT (100 ppm) were also submitted to this analysis.

The protection factor was calculated as:

$$
\% \mathrm{PF}=(\mathrm{PIa} / \mathrm{PIc}) \times 100
$$

where $\mathrm{PF}=$ protection factor; PIa = IP of the oil with the vegetable extracts or standards; Plc = IP of the control (oil without the vegetable extracts or standards).

\subsection{Chromatographic Analysis}

\subsubsection{Removal of Outliers from Samples Using the Solid Phase Extraction (SPE) Technique}

The Solid Phase Extraction (SPE) technique was employed for the removal of sugars, which could mask the compounds of interest. This technique has been increasingly used because it is quick, efficient, and requires very small volumes of samples and solvents. LC-18 SPE cartridges ( $2 \mathrm{~g}$, Supelco, Bellefonte, PA, USA) were conditioned with methanol and acidic water $(\mathrm{pH}=2.0)$. Subsequently, $4 \mathrm{~mL}$ of each vegetable ethanol extract once again evaporated and redissolved in $4 \mathrm{~mL}$ of water were added to their respective cartridges. After the vegetable extract completely passed through, the column 
was washed with sufficient acidic water to remove the sugars. Compounds of interest were eluted with methanol into coded glass vials and their bands were identified under UV light.

\subsubsection{Derivatization-Formation of Trimethylsilyl Derivatives (TMS)}

Prior to the GC-MS analysis, the samples were submitted to a crucial stage called derivatization. GC-MS is only useful for the analysis of gases, volatile, and thermally stable substances. Samples not showing this profile, presenting high molecular weight compounds and/or strongly polar functional groups, require a derivatization procedure, a reaction which transforms a substance of interest into a product of similar chemical structure, called a derivative, presenting characteristics suitable for analysis [36]. Chemical derivatization is widely used to reduce the polarity of functional groups and facilitate their separation during GC-MS analysis.

The fractions obtained after purification were added to $100 \mu \mathrm{L}$ of derivatizing reagent MSTFA. The reaction mixture was homogenized and incubated at $70{ }^{\circ} \mathrm{C}$ for $10 \mathrm{~min}$. The reagent was evaporated under a stream of nitrogen and trimethylsilyl (TMS) derivatives were rediluted in hexane $(800 \mu \mathrm{L})$. After homogenization, the supernatant was transferred to a vial and injected into the GC-MS system.

\subsubsection{Gas Chromatography-Mass Spectrometry (GC-MS)}

GC-MS analyses of the vegetable extracts were performed on a gas chromatograph GC 2010 (Shimadzu Corp., Kyoto, Japan) coupled to a mass spectrometer QP 2010 Plus (Shimadzu Corp., Kyoto, Japan). Derivatized samples were separated using a capillary column (RTX-5MS $30 \mathrm{~m} \times$ $0.25 \mathrm{~mm} \times 0.25 \mu \mathrm{m})$. The temperature program started at $80{ }^{\circ} \mathrm{C}(1 \mathrm{~min})$, increasing at $20{ }^{\circ} \mathrm{C} / \mathrm{min}$ to $250{ }^{\circ} \mathrm{C}$, remaining at $250{ }^{\circ} \mathrm{C}$ for $1 \min (9 \min 30 \mathrm{~s})$, increasing at $6{ }^{\circ} \mathrm{C} / \mathrm{min}$ to $300{ }^{\circ} \mathrm{C}$, remaining at $300{ }^{\circ} \mathrm{C}$ for $5 \mathrm{~min}(13 \mathrm{~min} 20 \mathrm{~s})$, increasing at $15{ }^{\circ} \mathrm{C} / \mathrm{min}$ to $310^{\circ} \mathrm{C}$, remaining at $310{ }^{\circ} \mathrm{C}$ for $5 \mathrm{~min}$ ( $5 \mathrm{~min} 40 \mathrm{~s}$ ), increasing at $20{ }^{\circ} \mathrm{C} / \mathrm{min}$ to the final temperature of $320{ }^{\circ} \mathrm{C}$, remaining at $320{ }^{\circ} \mathrm{C}$ for $10 \mathrm{~min}(10 \mathrm{~min} 30 \mathrm{~s})$, totaling $40 \mathrm{~min}$ of analysis. Helium was used as the carrier gas, the injector temperature was $280{ }^{\circ} \mathrm{C}$, and the injection volume was $0.5 \mu \mathrm{L}$ in splitless mode. The interface was maintained at $280{ }^{\circ} \mathrm{C}$ and the detector was operated in the scanning mode $(\mathrm{m} / \mathrm{z} 40-800)$. Data integration was performed using the LabSolutions-GCMS software. Flavonoids, phenolic acids, and derivatives were identified by comparing their retention time and ion fragmentation with coded and authentic standards (quercetin, apigenin, kaempferol, kaempferide, rutin, epicatechin, catechin, resveratrol, ferulic acid, caffeic acid, $p$-coumaric acid, cinnamic acid) eluted under the same conditions as well as with the Wiley Version 8 library.

\subsection{Statistical Analysis}

The results obtained were statistically analyzed using the SAS software [37] and the analysis of variance using the general linear models (GLM) procedure. The Tukey test at 5\% probability was used for mean comparison. 


\section{Conclusions}

The amount of phenolic compounds present in the vegetables analyzed showed no direct relationship with the antioxidant activity in a large number of samples. Based on this finding, it is possible to affirm that different phenolic compounds and some non-phenolic substances present different antioxidant activities, and that the presence of high levels of certain classes of compounds in vegetables does not always guarantee higher antioxidant power. The highest correlation of the amount of phenolic compounds was found using the $\mathrm{DPPH}^{*}$ method. Lettuce, turmeric, watercress, and broccoli presented the highest antioxidant activity among the Brazilian vegetables analyzed.

The samples did not present the same results in all methodologies and no defined order of antioxidant activity could be found. One possible explanation for this could be the difference in the chemical composition of vegetables and different mediums and principles of analyses. Due to the great chemical diversity of the compounds found in this study, the use of more than one method is more suitable for the analysis of in vitro antioxidant activity of these vegetables.

Several phenolic compounds with high antioxidant activity could be identified using GC-MS in vegetables, mainly phenolic acids, some of them present in high concentrations, such as caffeic acid in spinach, chicory, and escarole.

\section{Acknowledgments}

The authors thank Solange G. C. Brazaca for her assistance in freeze-drying samples and the Fundação de Amparo à Pesquisa do Estado de São Paulo (FAPESP) (Process No. 2008/52834-4).

\section{References}

1. Sreeramulu, D.; Raghunath, M. Antioxidant activity and phenolic content of roots, tubers and vegetables commonly consumed in India. Food Res. Int. 2010, 43, 1017-1020.

2. Szeto, Y.T.; Kwok, T.C.; Benzie, I.F. Effects of a long-term vegetarian diet on biomarkers of antioxidant status and cardiovascular disease risk. Nutrition 2004, 20, 863-866.

3. Kähkönen, M.P.; Hopia, A.I.; Vuorela, H.J.; Rauha, J.P.; Pihlaja, K.; Kujala, T.S.; Heinonen, M. Antioxidant activity of plant extracts containing phenolic compounds. J. Agric. Food Chem. 1999, 47, 3954-3962.

4. Manach, C.; Scalbert, A.; Morand, C.; Rémésy, C.; Jiménez, L. Polyphenols: Food sources and bioavailability. Am. J. Clin. Nutr. 2004, 79, 727-747.

5. Roginsky, V.; Lissi, E.A. Review of methods to determine chain-breaking antioxidant activity in food. Food Chem. 2005, 92, 235-254.

6. Halliwell, B.; Gutteridge, J.M.C. Free Radicals in Biology and Medicine, 2th ed.; Clarendon Press: Oxford, UK, 1989.

7. Nakatani, N. Antioxidants from Spices and Herbs. In Natural Antioxidants: Chemistry, Health Effects and Applications; Shahidi, F., Ed.; AOCS Press: Champaign, IL, USA, 1996; pp. 64-65.

8. Pokorný, J. Are natural antioxidants better - and safer - than synthetic antioxidants? Eur. J. Lipid Sci. Technol. 2007, 109, 629-642. 
9. Sánchez-Moreno, C. Review: Methods used to evaluate the free radical scavenging activity in foods and biological systems. Food Sci. Technol. Int. 2002, 8, 121-137.

10. Magalhães, L.M.; Segundo, M.A.; Reis, S.; Lima, J.L.F.C. Methodological aspects about in vitro evaluation of antioxidant properties. Anal. Chim. Acta 2008, 613, 1-19.

11. Karadag, A.; Ozcelik, B.; Saner, S. Review of methods to determine antioxidant capacities. Food Anal. Methods 2009, 2, 41-60.

12. Huang, D.; Ou, B.; Prior, R.L. The chemistry behind antioxidant capacity assays. J. Agric. Food Chem. 2005, 53, 1841-1856.

13. Frankel, E.N.; Meyer, A.S. The problems using one-dimensional methods to evaluate multifunctional food and biological antioxidants. J. Sci. Food Agric. 2000, 80, 1925-1941.

14. Oliveira, A.C.; Valentim, I.B.; Goulart, M.O.F.; Silva, C.A.; Bechara, E.J.H.; Trevisan, M.T.S. Fontes vegetais naturais de antioxidantes. Quim. Nova 2009, 32, 689-702.

15. Becker, E.M.; Nissen, L.R.; Skibsted, L.H. Antioxidant evaluation protocols: Food quality or health effects. Eur. Food Res. Technol. 2004, 219, 561-571.

16. Ou, B.; Huang, D.; Hampsch-Woodill, M.; Flanagan, J.A.; Deemer, E.K. Analysis of antioxidant activities of common vegetables employing oxigen radical absorbance capacity (ORAC) and ferric reducing antioxidant power (FRAP) assays: A comparative study. J. Agric. Food Chem. 2002, 50, 3122-3128.

17. Re, R.; Pellegrini, N.; Proteggente, A.; Pannala, A.; Yang, M.; Rice-Evans, C. Antioxidant activity applying an improved ABTS radical cation decolorization assay. Free Radic. Biol. Med. 1999, 26, 1231-1237.

18. Assimopoulou, A.N.; Sinakos, Z.; Papageorgiou, V.P. Radical scavenging activity of Crocus sativus L. extract and its bioactive constituents. Phytother Res. 2005, 19, 997-1000.

19. Nilsson, J.; Pillai, D.; Önning, G.; Persson, C.; Nilsson, A.; Åkesson, B. Comparison of the 2,2'-azinobis-3-ethylbenzotiazoline-6-sulfonic acid (ABTS) and ferric reducing anti-oxidant power (FRAP) methods to assess the total antioxidant capacity in extracts of fruits and vegetables. Mol. Nutr. Food Res. 2005, 49, 239-246.

20. Zhou, K.; Yu, L. Total phenolic contents and antioxidant properties of commonly consumed vegetables grown in Colorado. Food Sci. Technol. 2006, 39, 1155-1162.

21. Roy, M.K.; Takenaka, M.; Isobe, S.; Tsushida, T. Antioxidant potential, anti-proliferative activities, and phenolic content in water-soluble fractions of some commonly consumed vegetables: Effects of thermal treatment. Food Chem. 2007, 103, 106-114.

22. Llorach, R.; Martínez-Sánchez, A.; Tomás-Barberán, F.A.; Gil, M.I.; Ferreres, F. Characterisation of polyphenols and antioxidant properties of five lettuce varieties and escarole. Food Chem. 2008, $108,1028-1038$.

23. Chu, Y.F.; Sun, J.; Wu, X.; Liu, R.H. Antioxidant and antiproliferative activities of common vegetables. J. Agric. Food Chem. 2002, 50, 6910-6916.

24. Gobbo-Neto, L.; Lopes, N.P. Plantas medicinais: Fatores de influência no conteúdo de metabólitos secundários. Quim. Nova 2007, 30, 374-381.

25. Sreejayan, N.; Rao, M.N.S. Curcuminoids as potent inhibitors of lipid peroxidation. J. Pharm. Pharmacol. 1994, 46, 1013-1016. 
26. Kuttan, R.; Bhanumathy, P.; Nirmala, K.; George, M.C. Potential anticancer activity of turmeric (Curcuma longa). Cancer Lett. 1985, 29, 197-202.

27. Bachmeier, B.E.; Mohrenz, I.V.; Mirisola, V.; Schleicher, E.; Romeo, F.; Höhneke, C.; Jochum, M.; Nerlich, A.G.; Pfeffer, U. Curcumin downregulates the inflammatory cytokines CXCL1 and -2 in breast cancer cells via NFkB. Carcinogenesis 2008, 29, 779-789.

28. Kukić, J.; Popović, V.; Petrović, S.; Mucaji, P.; Ćirić, A.; Stojković, D.; Soković, M. Antioxidant and antimicrobial activity of Cynara cardunculus extracts. Food Chem. 2008, 107, 861-868.

29. DuPont, M.S.; Mondin, Z.; Willamson, G.; Price, K.R. Effect of variety, processing, and storage on the flavonoid glycoside content and composition of lettuce and endive. J. Agric. Food Chem. 2000, 48, 3957-3964.

30. Singleton, V.L.; Orthofer, R.; Lamuela-Raventós, R.M. Analysis of total phenols and other oxidation substrates and antioxidants by means of Folin-Ciocalteau reagent. Methods Enzymol. 1999, 299, 152-178.

31. Moraes-de-Souza, R.A.; Oldoni, T.L.C.; Regitano-d'Arce, M.A.B.; Alencar, S.M. Antioxidant activity and phenolic composition of herbal infusions consumed in Brazil. Cienc. Tecnol. Aliment. 2008, 6, 41-47.

32. Mensor, L.L.; Menezes, F.S.; Leitão, G.G.; Reis, A.S.; Santos, T.C.; Coube, C.S.; Leitão, S.G. Screening of Brazilian plant extracts for antioxidant activity by the use of DPPH free radical method. Phytother. Res. 2001, 15, 127-130.

33. Emmons, C.L.; Peterson, D.M.; Paul, G.L. Antioxidant capacity of oat (Avena sativa L.) extracts. 2. In vitro antioxidant activity and content of phenolic and tocol antioxidants. J. Agric. Food Chem. 1999, 47, 4894-4898.

34. Benzie, I.F.F.; Strain, J.J. The ferric reducing ability of plasma (FRAP) as a measure of "antioxidant power": The FRAP assay. Anal. Biochem. 1996, 239, 70-76.

35. American Oil Chemists' Society (AOCS). Official Methods and Recommended Practices, 5th ed.; AOCS: Champaign, IL, USA, 1999.

36. Bonatto, P.S. Cromatografia Gasosa. In Fundamentos de Cromatografia; Collins, C.H., Braga, G.L., Bonatto, P.S., Eds.; Unicamp: Campinas, Brazil, 2006; pp. 203-270.

37. SAS Institute. SAS Version 9.0; SAS Institute: Cary, NC, USA, 2002.

(C) 2012 by the authors; licensee MDPI, Basel, Switzerland. This article is an open access article distributed under the terms and conditions of the Creative Commons Attribution license (http://creativecommons.org/licenses/by/3.0/). 